\title{
SOCIOECONOMIC DETERMINANTS OF FERTILITY: A CROSS DISTRICTS ANALYSIS OF PUNJAB, PAKISTAN
}

\author{
MUHAMMAD QASIM ATTARI \\ Ph.D. Scholar, \\ National College of Business Administration and \\ Economics (NCBA\&E), Lahore, Pakistan \\ Email: mqasim_attari@yahoo.com \\ ZAHID PERVAIZ \\ Assistant Professor, Department of Economics, \\ National College of Business Administration and \\ Economics (NCBA\&E), Lahore, Pakistan \\ Email: ecozahid@yahoo.com \\ AMATUL R. CHAUDHARY \\ Professor/Dean School of Social Sciences, \\ National College of Business Administration and \\ Economics (NCBA\&E), Lahore, Pakistan \\ Email: amatulrchaudhary@ncbae.edu.pk
}

\begin{abstract}
This study has investigated various socio-economic and demographic determinants of fertility across the districts of Punjab, Pakistan. Gross Domestic Product (GDP) per capita, population density, female literacy rate, employment rate and child mortality have been identified as determinants of fertility by using cross sectional regression. The results of this study indicate that Gross Domestic Product (GDP) per capita and population density have negative and insignificant whereas female literacy rate has negative and significant association with fertility. On the other hand employment rate and child mortality have positive association with fertility. According to results of this study, increase in female education and reduction in child mortality can be helpful to reduce fertility in the districts of Punjab.
\end{abstract}

Keywords: Fertility, GDP Per Capita, Population Density, Female Literacy, Child Mortality, Employment Rate

JEL Classification Codes: J13, O40, J19, I21, J13, J64

\section{INTRODUCTION}

Family economics has number of socio-economic implications at micro and macro level. The compositions of population play an important role in socio-economic development across the countries and within a country or region. Normally, demographers 
made their predictions about fertility simply on the basis of past trends or on the basis of changes in the age-sex- marital composition of the population. Different socio-economic contemplations have neglected. Population size, composition and its growth are interlinked with different socio-economic indicators. Different socio-economic researchers highlighted different channels of these linkages from various perspectives. According to Becker (1960) may for some parents, children are a source of income and they get satisfaction from the earning of their children. On the other hand a family must determine not only how many children it has but also the amount spent on them. Some parents have desire the quality of their children with the provision of quality education at primary, college and university level and better health facilities. So, increase in parental income would increase the expenditures on children because the children are not an inferior good for parents. Thus an increase in income should increase both the quantity and quality of children. But it is observed that the quantity elasticity is small as compared to the quality elasticity.

Education is considered as one the important determinants of fertility. Different studies indicated different channels about the role of education to determine fertility among the countries and within a country. First, education especially women education raises a woman's permanent income through earnings which is helpful in the optimal decision about fertility keeping the quality of children in mind (Becker 1960; Mincer 1963; Becker and Lewis 1974 and Willis 1973). Second, education may improve an individual's knowledge about the healthy pregnancy behaviors; fertility choices and different socio-economic consequences (Grossman,1972).The age at first marriage, literacy status, child mortality, mass media exposure and wealth status also have importance to determine fertility across the different regions. Normally, high child mortality leads high fertility desire by mothers (Adhikari, 2010). So, for appropriate prediction about birth rates and to study fertility differentials across the countries and among the different regions of a country socioeconomic considerations are very important.

The population growth in Pakistan is comparatively high from other developing countries. Now, at this time Pakistan is the sixth most populous country in the world with anticipated population of 188 million. According to the projection about the population of Pakistan in 2050, it expected that it will retain the same position with 363 million. The growth rate of population is 1.95 percent which is comparatively high than average growth rate of South Asian countries. The basic reason behind the differences among the growth 
rates of population in Pakistan and other South Asian countries is high fertility rate. Total fertility rate in Bangladesh 2.3 percent, in Bhutan 2.6 percent, in China 1.5 percent, in India 2.4 percent, in Maldives 2.3 percent, in Nepal 2.6 percent, in Sri Lanka 2.1 percent and in Pakistan is 3.2 percent (Pakistan Economic Survey, 2014). On the other hand it is observed that there are fertility differentials across the rural and urban, in former total fertility rate is 4.2 percent but in later is 3.2 percent (Pakistan Demographic and Health Survey PDHS, 2013). Fertility differentials have also observed within provinces. Punjab is the most populated province of Pakistan. More than half of the population of Pakistan resides in Punjab. The fertility differentials across the districts of Punjab are also clearly observable (Multiple Indicator Cluster Survey MICS, 2012).

It is important to study determinants of fertility across the different regions of a country like Pakistan where population growth is high. There are number of socioeconomic, demographic and cultural factors which may be held responsible for fertility differentials across the regions. The present study tries to investigate some socio-economic determinants of fertility. Female literacy, child mortality, employment rate, Gross Domestic Product (GDP) per capita and population density have considered as determinants of fertility differentials across the districts of Punjab.

\section{REVIEW OF LITERATURE}

There are number of studies that have been analyzed the phenomenon of fertility differentials and its determinants across the countries and among the different regions of a countries. Some studies have been investigated determinants of fertility across the time also. Recently, many socio-economic researchers have been studied the importance of women empowerment in the variation of fertility across the time and across the regions. In literature, the impact of different dimensions of women empowerment like female education, labor force participation, political participation on fertility. Neoclassical economists highlighted that enhancement in human capital formation increased women empowerment which decreased demand for children (Singh, 1994). Different studies indicated that female education negatively associated with fertility across the countries and across the different regions of a country (Schultz, 1973; Ainsworth et al., 1996; Vavrus and Larsen, 2003; Sackey, 2005). Some other empirical evidence also suggested that more educated women demanded fewer children (Schultz, 1973; Singh, 1994). Schultz (1973) identified small family size where female education was high. According to United Nations 
(1985) female labor force participation had negative association with fertility. Child caring and home work required time and energy from mothers, but when mothers would be educated their opportunity cost will be high, they would prefer on fewer children. So, more education, urbanization and modernization would reduce fertility (Ellis, 1988). Bettio and Villa (1998) investigated the relationship between unemployment and fertility in Italy. They used unemployment rate and total fertility rate to examine the association. After empirical analysis they found negative association between total fertility and unemployment rate in Italy.

Yohannis, Yemane and Worku (2003) studied fertility differentials among the different regions of Ethiopia. They investigated some demographic, religion and socioeconomic determinants of fertility differentials across the regions. Ethnicity, religion, female education, use of contraceptives, early marriages, child mortality and income were considered as determinants of fertility differentials. They used cross sectional regression to investigate the impact of mentioned factors on total fertility. There results indicated child mortality and early marriages were positively and significantly associated with total fertility whereas income, female education and use of contraceptives were negatively and significantly associated with total fertility. Ethnicity and religion were contributed significantly to determine fertility across the regions of Ethiopia.

Dey and Goswami (2009) investigated the determinants of fertility in North East India. Total fertility was considered as dependent variable whereas education, religion, occupation, economic status, child mortality, age at marriage, duration of breastfeeding and use of contraceptives were taken as determinants. They estimated two separate models, one for those couples who had experienced child loss and others who did not. The results of their study indicated that current age of women and age at marriage had significant and negative relationship with total fertility in both models whereas education of women and use of contraceptives had negative and significant association with total fertility in second model where women had no child loss. Status of women, child mortality had significant relationship with fertility, former had negative and later had positive association with fertility. Adhikari (2010) investigated fertility differentials in Nepal. He considered demographic, socio-economic and cultural factors as determinants of fertility differential. He found that age at marriage, fertility intentions, education, mass media exposure, economic status and child mortality had significant association with fertility in Nepal. Child mortality and fertility 
had strong positive association. He suggested that implementation of marital law of age, mass media exposure, improvement in education, reduction in child mortality, improvement in living standard of people and economic participation of women could be helpful to reduce fertility in Nepal. Some other studies indicated that education of women, improvement in living standard, unemployment and urbanization had negative association with fertility whereas child mortality and early marriages had positive association with fertility (Singh, et al., 2012 and Dribe, et al., 2014).

\section{THEORETICAL FRAMEWORK AND METHODOLOGY}

An overview of existing literature shows that there are various factors which may be held responsible for fertility differentials across the countries and among the regions of a country. Present study investigates some socio-economic determinants of fertility differentials among the districts of Punjab, Pakistan. This study uses total fertility rate as dependent variable and GDP per capita, female literacy rate, employment rate, child mortality rate and population density are considered as the determinants. GDP per capita may reduce fertility by increasing expenditures on the quality of children. Normally, after increase in income, parents increase their expenditures on education and health of their children to enhance the quality of their children; this would reduce the demand for children (Becker, 1960). Educated women may have lower demand for children due to increase their opportunity cost of having children (Schultz, 1973). Employment rate may have positive associative with fertility because it would increase the marriage rate which may increase fertility (Bettio and Villa, 1998). Similarly, child mortality may increase fertility by increasing the parental demand for children after child death experience (Dey and Goswami, 2009). Population density may reduce fertility because it has some indirect channels. Productivity of human capital is higher in those regions where population density is high. So, population density increases investment in human capital and promotes human development (Becker et al., 1999). May increase in human capital development reduce fertility by increasing opportunity cost of having children (Adhikari, 2010). This shows that GDP per capita, female literacy, employment rate, child mortality and population density may lead to differences in fertility.

This study investigates the impact of GDP per capita, female literacy, employment rate, population density and child mortality on total fertility. The study uses a regression model that discovers the determinants of fertility across the districts. The regression model 
is estimated using Ordinary Least Square (OLS) method. The model use for the present study is given below:

$T F R_{i}=\left(P D_{i}, Y_{i}, F L R_{i}, E M R_{i}, C M_{i}\right)$

$T F R_{i}=\alpha+\beta_{1} P D_{i}+\beta_{2} Y_{i}+\beta_{3} F L R_{i}+\beta_{4} E M R_{i}+\beta_{5} C M+\mu_{i}$

Where,

TFR = Total Fertility Rate of ith district.

PD = Population Density of ith district.

$Y=$ GDP per capita of ith district.

FLR = Female Literacy Rate of ith district.

EMR= Employment Rate of ith district.

$\mathrm{CM}=$ Child Mortality of ith district.

$i=1,2,3, \ldots \ldots ., 35$.

\section{A. DESCRIPTION AND CONSTRUCTION OF VARIABLES}

Total fertility rate is used as dependent variables whereas female literacy, GDP per capita, child mortality, employment rate and population density are used as independent variables. Different variables are operationalized differently, for female literacy ten years and above female literacy rate is used. To calculate GDP per capita in terms of purchasing power parity (PPP\$), we have used method proposed by UNDP (2003) at district level in Pakistan. To attain real GDP (PPP\$) per capita for thirty-five districts of Punjab, we added agriculture-crop value and manufacturing value added of each district. Then this sum has been divided on the same at national level to obtain ratio of district income to the national income. This ratio is then multiplied to real GDP (PPP\$) of Pakistan in order to attain district real GDP (PPP\$). In last round, real GDP (PPP\$) per capita for each district is obtained by dividing each district real GDP to the size of their respective population. Child mortality defines the number deaths of less than five year children per thousand and on the other hand total employment rate of fifteen years age people and above is considered for employment rate. Population density is mid-year population divided 
by land area in square kilometers. We have used population density (hundred people per square $\mathrm{km}$ ) for the districts of Punjab.

\section{B. DATA SOURCE}

Data of mentioned variables is collected from different sources. The data of total fertility, child mortality and employment rate is taken from Multiple Indicator Cluster Survey (MICS, 2012). Population density data is collected from Punjab Development Statistics (PDS, 2013). GDP per capita data is collected from Qasim and Chaudhary (2014).

\section{EMPIRICAL RESULTS AND DISCUSSION}

The results in table one indicate that population density, female literacy and GDP per capita have negative association with total fertility among the districts of Punjab. But both GDP per capita and population density have insignificant probability values however female literacy has significant relationship with total fertility. While other two variables child mortality and employment rate have positive coefficients.

Table 1: Determinants of Fertility across the Districts of Punjab

\begin{tabular}{|c|c|c|c|c|}
\hline Variable & Coefficient & $\begin{array}{c}\text { Standard } \\
\text { Errors }\end{array}$ & t-statistic & Probability \\
\hline Y & $-5.99 \mathrm{E}-05$ & $7.00 \mathrm{E}-05$ & -0.855818 & 0.3994 \\
\hline FLR & -0.022677 & 0.009465 & -2.395814 & 0.0235 \\
\hline EMR & 0.139183 & 0.053796 & 2.587258 & 0.0152 \\
\hline CM & 0.007926 & 0.003513 & 2.256420 & 0.0320 \\
\hline PD & -0.000154 & 0.000109 & -1.404400 & 0.1712 \\
\hline C & -9.747837 & 5.218251 & -1.868027 & 0.0723 \\
\hline R-squared & 0.5997 & Adjusted R-squared & 0.5140 \\
\hline F-statistic & 7.0005 & Prob.(F-statistic) & 0.0001 \\
\hline Durbin-Watson stat & 2.1219 & Included observations: & 35 \\
\hline Dependent Variable: TFR & \multicolumn{5}{l}{} \\
\hline
\end{tabular}

Source: calculated by authors

Table 2: Diagnostic Tests

\begin{tabular}{|c|c|c|}
\hline $\begin{array}{c}\text { Normality Test } \\
\text { (Jarque-Bera Statistic) }\end{array}$ & $\begin{array}{c}\text { Jarque-Bera } \\
\text { Statistic }=0.7145\end{array}$ & Probability $=0.6995$ \\
\hline $\begin{array}{c}\text { Model Specification Test } \\
\text { Ramsey RESET Test }\end{array}$ & F-statistics $=0.3739$ & Probability $=0.6917$ \\
\hline $\begin{array}{c}\text { Heteroskedasticity Test } \\
\text { (White Heteroskedasticity Test) }\end{array}$ & F-statistics $=0.8466$ & Probability $=0.6539$ \\
\hline $\begin{array}{c}\text { Serial Correlation } \\
\text { (Breush-Godfrey Serial } \\
\text { Correlation LM Test) }\end{array}$ & F-statistics $=0.6477$ & Probability $=0.6339$ \\
\hline
\end{tabular}


Diagnostic tests indicate that error term is normally distributed, model is correctly specified and there is no Heteroskedasticity, no serial correlation and no multicollinearity in model.

Table 3: Correlation Matrix

\begin{tabular}{|c|c|c|c|r|r|}
\hline Variables & PD & Y & EMR & \multicolumn{1}{c|}{ FLR } & \multicolumn{1}{c|}{ CM } \\
\hline PD & 1.000000 & 0.385727 & 0.036130 & 0.395041 & -0.287556 \\
\hline Y & 0.385727 & 1.000000 & 0.011541 & -0.126485 & 0.055915 \\
\hline EMR & 0.036130 & 0.011541 & 1.000000 & 0.350388 & -0.341283 \\
\hline FLR & 0.395041 & -0.126485 & 0.350388 & 1.000000 & -0.649039 \\
\hline CM & -0.287556 & 0.055915 & -0.341283 & -0.649039 & 1.000000 \\
\hline
\end{tabular}

Source: calculated by authors

Figure 1: Plot of Cumulative Sum of Recursive Residuals

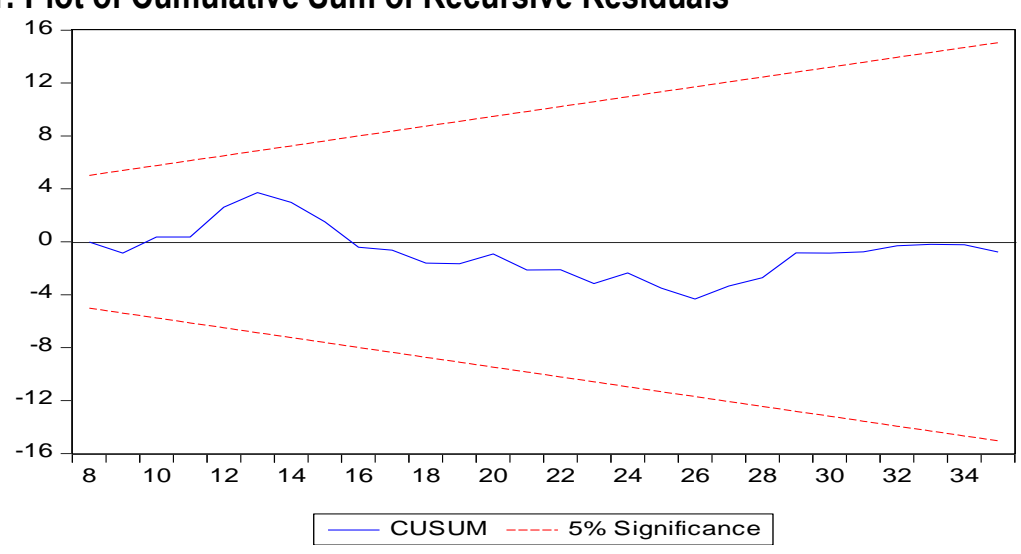

Figure 2: Plot of Cumulative Sum of Recursive Residuals

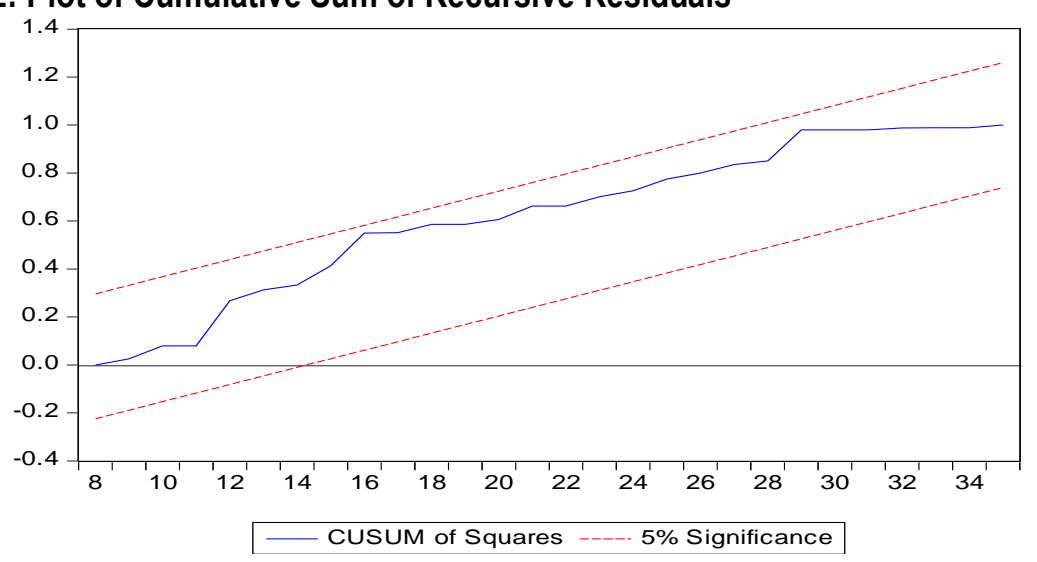

To analyze the stability of the coefficients together the cumulative sum (CUSUM) and the cumulative sum of squares (CUSUMSQ) are applied. The graphical representation of (CUSUM) and (CUSUMSQ) are shown in Figure 1 and 2. If the plot of these statistics remains within critical boundaries of the five percent significance level, the null hypothesis stating that the regression equation is correctly specified cannot be rejected. The results of 
the Figure 1 and 2 indicate that the plots of both statistics (CUSUM) and (CUSUMSQ) are within the boundaries, so it is clear that our model is correctly specified.

\section{CONCLUSIONS AND RECOMMENDATIONS}

In this paper cross sectional regression was used to investigate the impact of different socioeconomic factors on fertility among the districts of Punjab. For this analysis total fertility rate was used as dependent variable whereas Gross Domestic Product (GDP) per capita, female literacy rate, employment rate, child mortality and population density were considered as determinants.

Empirical results of this study indicate that Gross Domestic Product (GDP) per capita and population density have negative and insignificant whereas female literacy rate has negative and significant association with fertility. On the other hand employment rate and child mortality have positive association with fertility. According to results of this study, increase in female education and reduction in child mortality can be helpful to reduce fertility in the districts of Punjab. Female education has strong impact on fertility even we have used female literacy rate as proxy for female education. The coefficient of female literacy shows that one unit increase in female literacy will reduce total fertility by .022 units. We also find that child mortality has significant association with fertility. Child survival can reduce fertility among the districts of Punjab. It is recommended to Punjab government that improvement in human wellbeing especially women wellbeing through education and job opportunities may a best policy option to reduce fertility among the different regions of Punjab. Public provision of social services related to education, health can increase human wellbeing and child survival that can be useful to reduce fertility.

\section{REFERENCES}

Adhikari, R. (2010). Demographic, socio-economic, and cultural factors affecting fertility differentials in Nepal. BMC pregnancy and childbirth, 10(1), 1.

Ainsworth, M., Beegle, K., and A. Nyamete, (1996). The Impact of Womenes Schooling on Fertility and Contraceptive Use: A Study of Fourteen Sub-Saharan African Countries." The World Bank Economic Review, 10(1), 85-122.

Becker, G. S. (1960). An economic analysis of fertility. In Demographic and economic change in developed countries (pp. 209-240). Columbia University Press.

Becker, G.S and Lewis, H.G. (1974). On the interaction between the quantity and quality of children. Journal of Political Economy 81 (2), 279-288. 
Becker, G.S. Glaeser, E.L. and Murphy, K.M. (1999). Population and economic growth. The American Economic Review, 89(2), 145-149.

Bettio F.and Villa P. (1998). A Mediterranean Perspective on the Breakdown of the Relationship between Participation and Fertility. Cambridge Journal of Economics, 22(2), 137-171.

Dey, S., \& Goswami, S. (2009). Fertility pattern and its correlates in north-east India. J. Hum. Ecol, 26(2), 145-52.

Dribe, M., Hacker, J. D., \& Scalone, F. (2014). The impact of socio-economic status on net fertility during the historical fertility decline: A comparative analysis of Canada, Iceland, Sweden, Norway, and the USA.Population studies, 68(2), 135-149.

Fitaw, Y., Berhane, Y., \& Worku, A. (2003). Differentials of fertility in rural Butajira. Ethiopian Journal of health development, 17(1), 17-25.

Government of Pakistan (2013). Pakistan Demographic and Health Survey, Federal Bureau of Statistics, Islamabad.

Government of Pakistan, Economic Survey of Pakistan (various Issues). Islamabad, Pakistan: Finance Division.

Government of Punjab (2012). Multiple Indicator Cluster Survey, Bureau of Statistics, Lahore.

Government of Punjab (2012). Punjab Development Statistics, Bureau of Statistics, Lahore.

Grossman, M. (1972). On the concept of health capital and the demand for health. Journal of Political economy, 80(2), 223-255.

Mincer, J. (1963). Market prices, opportunity costs, and income effects. Measurement in economics, 67-82.

Qasim, M. and Chaudhary, A.R. (2014). An Analysis of Inter-District Human Development Disparities in Punjab, Pakistan. M.Phil. thesis in Applied Economics, National College of Business Administration \& Economics (NCBA\&E) Lahore, Pakistan.

Sackey H.A. (2005). Female Labour force Participation in Ghana: The Effects of Education. African Economic Research Consortium Research Paper 150, Nairobi.

Schultz, T. P. (1973). Explanation of Birth Rate Changes of Space and Time. Journal of Political Economy. 81(2), 238 - 274.

Singh, P. K., Rai, R. K., Alagarajan, M., \& Singh, L. (2012). Determinants of maternity care services utilization among married adolescents in rural India. PloS one, 7(2), 235251.

Singh, R. D. (1994). Fertility-Mortality Variation Across LDCs: Women's Education, Labour Force Participation and Contraceptive Use. KYLOS. 47(2), 209-229.

UNDP (2003). Pakistan National Human Development Report. Karachi, Pakistan: Oxford University Press.

United Nations (1985). Women's Employment and Fertility: Comparative Analysis of World Fertility Survey Results for 38 Developing Countries. Population Studies No. 96. New York: Department of International Economic and Social Affairs, Population Division, United Nations. 
Vavrus, F. and Larsen, U. (2003). Girl's Education and Fertility Transition: An Analysis of Recent Trends in Tanzania and Uganda. Economic Development and Cultural Change. 51(4), 945-76.

Willis, R. J. (1973). A new approach to the economic theory of fertility behavior. Journal of political Economy, 81(2), S14-S64.

\section{APPENDIX A}

Figure 1

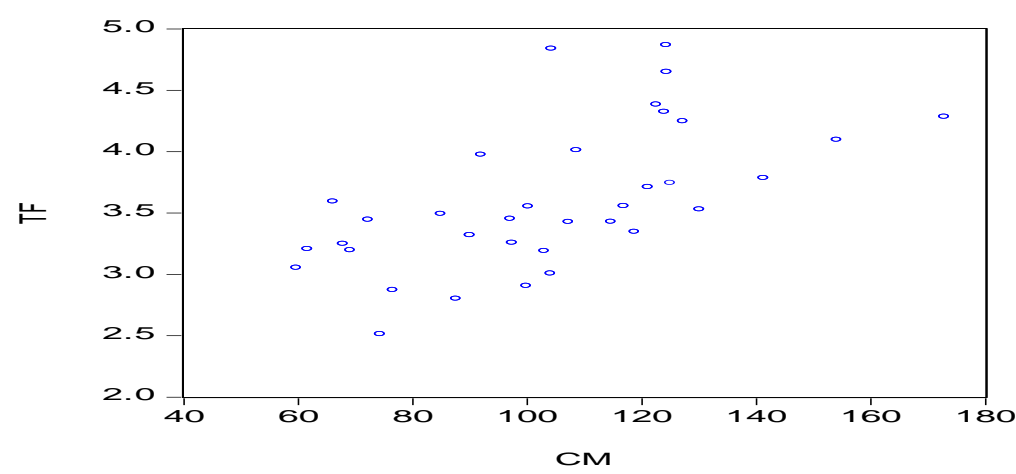

Figure 2

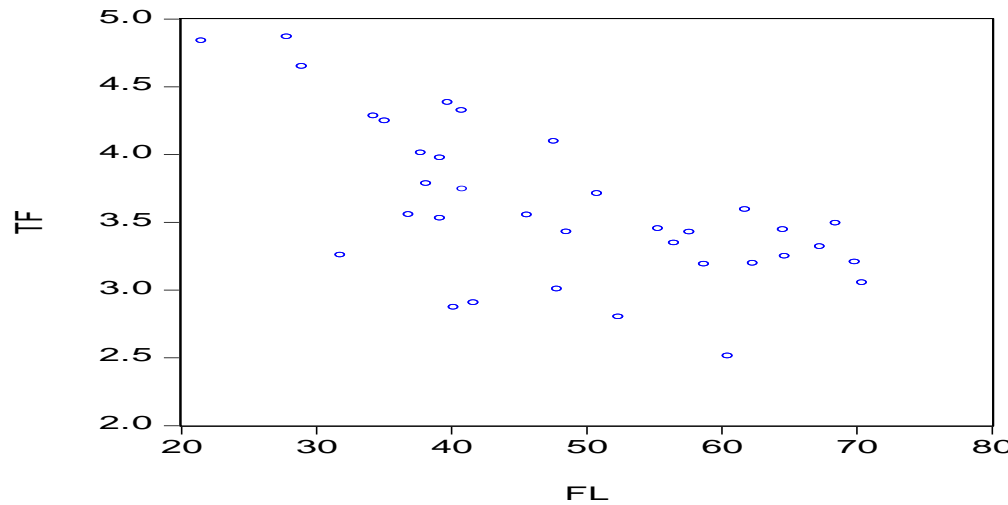

